\title{
Faecal microbiota transplantation for treatment of recurrent or refractory Clostridioides difficile infection in Hong Kong
}

\author{
Rashid N Lui, Sunny H Wong, Louis HS Lau, TT Chan, Kitty CY Cheung, Amy YL Li, ML Chin, \\ Whitney WY Tang, Jessica YL Ching, Kelvin LY Lam, Paul KS Chan, Justin CY Wu, Joseph JY Sung, \\ Francis KL Chan, Siew $\mathrm{C} \mathrm{Ng}$ *
}

\section{A B S T R A C T}

Introduction: Clostridioides difficile infection (CDI) is a leading cause of healthcare-associated infection globally, causing significant morbidity and mortality. Faecal microbiota transplantation (FMT) has emerged as a promising option for recurrent and refractory CDI. This study aimed to assess the safety, efficacy, and feasibility of FMT for CDI in Hong Kong.

Methods: We conducted a single-centre, retrospective study for all consecutive cases of recurrent or refractory CDI who underwent FMT from 2013 to 2018. Clinical demographics, outcome, and safety parameters were collected.

Results: A total of 24 patients with recurrent or refractory CDI (median age 70 years, interquartile range $=45.0-78.3$ years; $67 \%$ male) were included Over $80 \%$ had been recently hospitalised or were long-term care facility residents. Faecal microbiota transplantation was delivered by feeding tube in 11 (45.8\%), oesophagogastroduodenoscopy in eight (33.3\%), and colonoscopy in six (25\%) of the patients. Resolution of diarrhoea without relapse within 8 weeks was achieved in 21 out of 24 patients $(87.5 \%)$ after FMT. No deaths occurred within 30 days. The FMT was well tolerated and no serious adverse events attributable to FMT were reported.
Conclusion: Our results confirm that FMT is a safe, efficacious, and feasible intervention for patients with refractory or recurrent CDI in Hong Kong. Given the increasing disease burden and the lack of effective alternatives in Hong Kong for difficult-to-treat cases of CDI, we recommend that a territory-wide FMT service be established to address increasing demand for this treatment.

\section{Hong Kong Med J 2019;25:178-82}

https://doi.org/10.12809/hkmj197855
${ }^{1}$ RN Lui, MB, ChB, FHKAM (Medicine)
${ }^{2,3}$ SH Wong, DPhil (Oxon), FHKAM (Medicine)
'LHS Lau, MB, ChB, MRCP (UK)
${ }^{1} \mathrm{TT}$ Chan, MB, BS, MRCP (UK)
${ }^{2} \mathrm{KCY}$ Cheung, BSc, MPH
${ }^{2} \mathrm{ALi}, \mathrm{BSC}$
${ }^{4}$ ML Chin, BSc, MPhil
${ }^{2}$ W Tang, MPhil, MPH
2 JYL Ching, BSN, MPH
${ }^{1}$ KLY Lam, MB, BS, FHKAM (Medicine)
3,4 PKS Chan, MD, FRCPath
2 JCY Wu, MD, FRCP (Edin)
JJY Sung, MD, PhD
${ }^{2,3}$ FKL Chan, MD, FRCP (Edin)
${ }^{2,3} \mathrm{SC} \mathrm{Ng}$ *, PhD, FRCP (Edin)
Division of Gastroenterology and Hepatology, Department of Medicine and Therapeutics, Prince of Wales Hospital, Shatin, Hong Kong
${ }^{2}$ Institute of Digestive Disease, The Chinese University of Hong Kong, Shatin, Hong Kong
Centre for Gut Microbiota Research, The Chinese University of Hong Kong, Shatin, Hong Kong
${ }^{4}$ Department of Microbiology, The Chinese University of Hong Kong, Shatin, Hong Kong
* Corresponding author: siewchienng@cuhk.edu.hk

New knowledge added by this study

- Faecal microbiota transplantation is safe, efficacious, and feasible in Hong Kong.

Implications for clinical practice or policy

- This study raises awareness of this important armamentarium for the treatment of patients with recurrent or refractory Clostridioides difficile infection.

- A concerted effort by policymakers will be necessary if a dedicated centre providing territory-wide faecal microbiota transplantation services is to be established to help these difficult-to-treat patients.

\section{Introduction}

Clostridioides difficile infection (CDI) is a leading cause of healthcare-associated diarrhoea and is associated with significant morbidity and mortality. ${ }^{1}$ In the United States, $C$ difficile has become the most lethal acute enteric pathogen, with the Centers for Disease Control designating it as an urgent antibiotic resistance threat in 2015, one of only three pathogens to earn this distinction (http://www.cdc. gov/drugresistance/biggest_threats.html). ${ }^{2}$ In Hong Kong, an annual increase of $26 \%$ in CDI was noted from 2006 to $2014 .{ }^{3}$ This is even more alarming for 
older adults aged $\geq 65$ years, in whom the estimated crude incidence rate is 133 to 207 cases per 100000 population. ${ }^{4}$ It is believed that CDI arises when the normal gut microbiota is disrupted. This allows for the colonisation of $C$ difficile, whose production of cytotoxins leads to disease. ${ }^{5} \mathrm{~A}$ recent study showed that apart from microbiota dysbiosis, enteric virome dysbiosis may also play an important role. ${ }^{6}$ Risk factors include nursing home care, recent hospitalisation, antibiotics exposure, and protonpump inhibitor use. ${ }^{4}$ First-line treatment for nonfulminant $C$ difficile-associated diarrhoea includes the cessation of unnecessary medications and treatment with vancomycin or fidaxomicin. For more severe cases, a combination of vancomycin and intravenous metronidazole with early consideration of surgery may be required. ${ }^{7}$ However, it is well known that a significant proportion of cases relapse or recur despite first-line therapy. ${ }^{8}$ For recurrent cases, taper and pulse regimens of vancomycin can be offered, but response rates decline further with multiple recurrences. ${ }^{9}$ Fidaxomicin is another promising treatment option, but its usage is limited by its price and availability. ${ }^{10}$ These difficult-to-treat cases are associated with extended hospital stays and may result in widespread nosocomial outbreaks. In their seminal paper, van Nood et $\mathrm{al}^{11}$ demonstrated that faecal microbiota transplantation (FMT), in which infusion of faeces from healthy donors is given to individuals with disease, was efficacious for recurrent CDI. Since then, this finding has been confirmed by a systematic review and metaanalysis of $>160$ clinical studies. ${ }^{12}$ In view of the limited options available for treatment of recurrent or refractory cases, we decided to establish a pilot FMT service to address this treatment gap. Initially, screening of relatives meeting strict donor criteria and willing to donate fresh stools was performed; later on, with the establishment of the Healthy Donor Stool Biobank by the Faculty of Medicine, The Chinese University of Hong Kong in 2017, prescreened frozen stools were made available. The objectives of this study, the first of its kind in Hong Kong, was to assess the safety, efficacy, and technical and logistical feasibility of performing FMT.

\section{Methods}

We conducted a single-centre, retrospective review of all consecutive cases of recurrent or refractory CDI with FMT performed at an academic hospital from 2013 to 2018. Data on patient demographics, co-morbidities, route of administration of FMT, treatment efficacy, adverse events, and other relevant clinical data were extracted from the Clinical Management System of the Hospital Authority, Hong Kong or from review of case notes under the auspices of the FMT registry. Stringent donor criteria based on guidance and protocols were

\section{在香港使用粪便微生物移植治療復發或難治性 難辨梭菌感染}

雷諾信、黃曦、柳浩城、陳婷婷、張載欣、李盈莉、錢妙玲、 鄧詠欣、程月玲、林朗昕、陳基湘、胡志遠、沈祖堯、 陳家亮、黃秀娟

引言：難辨梭菌感染是全球最常見的醫院內感染。患者有機會呈現嚴 重症狀甚至死亡。粪便微生物移植有望可治療復發或難治性難辨梭菌 感染。本研究旨在探討在香港使用粪便微生物移植治療難辨梭菌感染 的安全性、功效及可行性

方法：這項回顧性研究分析2013年至2018年期間因患上復發或難治性 難辨梭菌感染而使用粪便微生物移植治療的案例, 並收集患者的臨床 症狀、人口統計學資料、結果及安全參數。

結果 : 研究期間共 24 宗病例 (年齡中位數 70 歲, 四分位數範圍 $=45$ 78.3 歲；67\%為男性）。超過八成患者有近期入院記錄或入住老年療 養院。進行糞便微生物移植的途徑包括：11名患者（45.8\%）用餵食 管，8名患者 $(33.3 \%)$ 用胃鏡，6名患者（25\%）用腸鏡。使用糞便 微生物移植後, 24 名患者當中有 21 名 $(87.5 \%)$ 痊癒而沒有在 8 周內 復發。30天內沒有死亡個案。糞便微生物移植的整體耐受性好, 沒有 記錄到有關嚴重不良反應。

結論：本研究確認在復發或難治性難辨梭菌感染患者使用粪便微生物 移植是安全、有效及可行。有見難辨梭菌感染的疾病負擔有上升趨勢 以及缺乏有效替代治療, 成立服務全港的粪便微生物移植中心來應對 是一個可以考慮的方案。

applied to fresh and frozen donor stool to ensure patient safety. ${ }^{13}$ Screening for viral hepatitis, bloodborne viruses, pathogenic bacteria, enteric viruses, syphilis, multidrug resistant organisms, Helicobacter pylori, Cdifficile, and parasites was performed (online supplementary Appendix). The FMT product was delivered either via a feeding tube or through scope channels during oesophagogastroduodenoscopy (OGD) or colonoscopy. Feeding tube position was confirmed prior to FMT delivery. For the OGD route, the endoscopist performed a routine OGD to ensure there were no ulcerations or other contraindications for FMT. Afterwards, the endoscopist tried to pass the scope as distally as possible (at least to the second or third parts of the duodenum) to minimise reflux of the FMT back into the stomach. During the procedure carbon dioxide for luminal insufflation was used to minimise gaseous distention, discomfort, and the urge to retch or vomit. Before FMT delivery, the patient is sat upright to minimise the risk of aspiration. For the colonoscopy route, the endoscopist performed a routine colonoscopy to ensure there are no large ulcers or other contraindications for FMT. Afterwards, the endoscopist tried to pass the scope as proximally as possible, but if the patient's tolerance was an issue, administering FMT into the left side of the colon or even the 
rectum was considered reasonable, depending on the premorbid state. The majority of FMT procedures were performed in the Endoscopy Centre with close monitoring, followed by further observation in the wards for any potential adverse events. The present report was compiled in accordance with the PROCESS statement. ${ }^{14}$

\section{Results}

A total of 24 patients with recurrent or refractory CDI who received FMT were identified. The patients' baseline characteristics are shown in the Table. Their median age was 70 years (interquartile range $=45.0-78.3$ years $)$. More than two-thirds of the patients were male. More than half of the patients were in either a bedridden or chair-bound state, a surrogate of poor functional status. The majority (>80\%) of patients had been hospitalised within the most recent 3 months or were long-term care facility residents. All patients had at least one co-morbidity. The most common co-morbidity was hypertension $(\mathrm{n}=10,41.7 \%)$, followed by inflammatory bowel disease (IBD) $[n=6,25.0 \%]$ and stroke $(n=5$, $20.8 \%$ ). The FMT was performed by experienced gastroenterologists in accordance with published protocols ${ }^{11}$ and the latest guidelines. ${ }^{15}$ All patients were given $50 \mathrm{~g}$ of FMT product unless otherwise stated. The FMT was delivered via feeding tube in 11 (45.8\%), OGD in eight (33.3\%), and colonoscopy in six $(25.0 \%)$ of the patients (one patient had FMT performed via both OGD and colonoscopy during the same session). Resolution of diarrhoea without relapse within 8 weeks was achieved in 21 out of 24 patients $(87.5 \%)$. Three patients $(12.5 \%)$ did not show significant improvement in their symptoms after the therapy; therefore, a clinical decision was made to perform repeat FMT, after which all three patients showed resolution of diarrhoea. Two of those were confirmed $C$ difficile-negative on repeat stool testing; the remaining patient was frail and did not save repeat stools, but no documented recurrence within 8 weeks was noted. No deaths occurred at 30 days. The procedure was generally well tolerated, with no serious adverse events attributable to FMT. The most common complication was abdominal pain $(\mathrm{n}=3,12.5 \%)$ after FMT. Bloating was reported in one $(4.2 \%)$ patient.

\section{Discussion}

Because it replenishes colonic microbial diversity, FMT removes ecological niches that would otherwise be occupied by $C$ difficile. ${ }^{16} \mathrm{~A}$ recent study has shown that the prevalence of CDI in Asia is similar to the high prevalence in North America and Europe. ${ }^{17}$ Furthermore, it is well known that the treatment efficacy of antibiotics declines with multiple recurrences, ${ }^{9}$ rendering them less effective
TABLE. Patient data*

\begin{tabular}{|c|c|}
\hline Age, median (interquartile range), years & $70(45.0-78.3)$ \\
\hline Male & $16(66.7 \%)$ \\
\hline Smoker or ex-smoker & $12(50.0 \%)$ \\
\hline Drinker or ex-drinker & $3(12.5 \%)$ \\
\hline Bedridden/chair-bound status & $13(54.2 \%)$ \\
\hline $\begin{array}{l}\text { Hospitalisation within } 3 \text { months or long- } \\
\text { term care facility resident }\end{array}$ & $20(83.3 \%)$ \\
\hline \multicolumn{2}{|l|}{ Co-morbidities } \\
\hline Hypertension & $10(41.7 \%)$ \\
\hline Diabetes & $2(8.3 \%)$ \\
\hline Ischaemic heart disease & $2(8.3 \%)$ \\
\hline Gout & $3(12.5 \%)$ \\
\hline Liver disease & $2(8.3 \%)$ \\
\hline Renal failure & $3(12.5 \%)$ \\
\hline Inflammatory bowel disease & $6(25.0 \%)$ \\
\hline History of colorectal surgery & $2(8.3 \%)$ \\
\hline Gastrointestinal malignancy & $2(8.3 \%)$ \\
\hline Pseudo-obstruction & $1(4.2 \%)$ \\
\hline Other enteric infection & $1(4.2 \%)$ \\
\hline Stroke & $5(20.8 \%)$ \\
\hline Parkinson's disease & $3(12.5 \%)$ \\
\hline Chronic obstructive pulmonary disease & $3(12.5 \%)$ \\
\hline Systemic lupus erythematosus & $1(4.2 \%)$ \\
\hline Anxiety & $1(4.2 \%)$ \\
\hline Depression & $2(8.3 \%)$ \\
\hline Schizophrenia & $2(8.3 \%)$ \\
\hline \multicolumn{2}{|l|}{ Route of administration $†$} \\
\hline Feeding tube & $11(45.8 \%)$ \\
\hline Esophagogastroduodenoscopy & $8(33.3 \%)$ \\
\hline Colonoscopy & $6(25.0 \%)$ \\
\hline Resolution of diarrhoea & $21(87.5 \%)$ \\
\hline $\begin{array}{l}\text { Need for repeat faecal microbiota } \\
\text { transplantation }\end{array}$ & $3(12.5 \%)$ \\
\hline \multicolumn{2}{|l|}{ Adverse events } \\
\hline Death at 30 days & 0 \\
\hline Serious adverse events & 0 \\
\hline \multicolumn{2}{|l|}{ Other complications } \\
\hline Bloating & $1(4.2 \%)$ \\
\hline Abdominal discomfort or pain & $3(12.5 \%)$ \\
\hline
\end{tabular}

* Data are shown as No. (\%) of subjects, unless otherwise specified

+ One patient underwent concomitant faecal microbiota transplantation via both esophagogastroduodenoscopy and colonoscopy

in difficult-to-treat cases. We established Hong Kong's first FMT service to address the treatment gap that currently exists. Our results suggest that the efficacy of FMT for recurrent or refractory CDI is 
comparable to that reported in the literature, with an excellent safety profile. ${ }^{11,12}$

According to the Census and Statistics Department, the population of Hong Kong is projected to increase from 6.8 million in mid-2003 to 8.38 million in mid-2033 with a continuous ageing trend. ${ }^{18}$ The proportion of those aged $\geq 65$ years is projected to rise markedly, from $11.7 \%$ in 2003 to $27 \%$ in 2033. Life expectancy in Hong Kong has already increased to age 79.5 years, behind only Japan and Switzerland. ${ }^{18}$ Increasing numbers of elderly people living in residential care homes, together with the widespread use of antibiotics and proton-pump inhibitors ${ }^{4}$, mean that the incidence of CDI in elderly people will likely increase in Hong Kong, as it has in other developed countries. ${ }^{18}$

The incidence of IBD in Hong Kong has risen by almost 3 -fold in the past two decades. ${ }^{19}$ Recently in the West, as the incidence and severity of CDI has increased in the general population, even greater increases have been described in patients with IBD. ${ }^{2}$ In the present study, a significant proportion of patients with CDI also had IBD, and it is likely that the incidence and severity of CDI in IBD patients in Hong Kong will increase further in future. Establishment of FMT services has been advocated for healthcare systems to effectively manage expected increases in refractory or recurrent $\mathrm{CDI}{ }^{20}$

A concerted effort by policymakers will be necessary to establish a dedicated centre to provide territory-wide FMT services to tackle the growing disease burden. Such a centre would require a multidisciplinary team involving gastroenterologists, microbiologists, infectious disease specialists, specialty nurses, and research personnel together with the cooperation of wards, the healthy donor stool biobank, and endoscopy centres. Such an FMT centre may receive territory-wide consultations and referrals. It could also provide training, knowledge transfer, and accreditation to healthcare professionals. Currently, the status of FMT as a therapeutic agent is still evolving. The United States Food and Drug Administration classifies human stool as a biological agent and asserts that its use in FMT should be regulated, although their draft guidance mentions that it intends to exercise enforcement discretion for its use in recurrent CDI that does not respond to standard therapies. ${ }^{21}$ This highlights the importance of proper oversight and governance to mitigate any potential risks that may arise. Data on long-term safety outcomes are also scarce, highlighting the importance and role of registries to provide more insight, another function a centralised and specialised FMT centre would be able to undertake.

Our study has several limitations. As a case series, the data presented are mainly descriptive and uncontrolled with the possibility of bias. Further, the sample size is relatively small. Controlled trials with a larger sample size are required to confirm these findings and to optimise the timing of FMT administration. Despite these limitations, resolution of diarrhoea was at a similar rate in the present study to that reported in the literature ${ }^{11}$ Furthermore, as the only centre in Hong Kong that has provided FMT, the results reported here would be highly relevant for both clinicians and policymakers concerning its safety, efficacy, and feasibility.

\section{Conclusion}

Our results show that FMT is safe, efficacious, and feasible for treating patients with recurrent or refractory CDI in Hong Kong. Given the lack of effective alternatives for difficult-to-treat cases of CDI, and demographic trends that will likely lead to increased incidence of CDI, demand for FMT is expected to rise. A territory-wide FMT service should be established to address this expected increase in demand.

\section{Author contributions}

All authors had full access to the data, contributed to the study, approved the final version for publication, and take responsibility for its accuracy and integrity.

Concept or design of the study: All authors.

Acquisition of data: RN Lui, LHS Lau, KCY Cheung.

Analysis or interpretation of data: RN Lui, LHS Lau, KCY Cheung.

Drafting of the manuscript: RN Lui, SH Wong, PKS Chan, SC $\mathrm{Ng}$.

Critical revision for important intellectual content: All authors.

\section{Conflicts of interest}

All authors have disclosed no conflicts of interest.

\section{Funding/support}

This research received no specific grant from any funding agency in the public, commercial, or not-for-profit sectors.

\section{Ethics approval}

The present study was reviewed and approved by the Joint Chinese University of Hong Kong/New Territories East Cluster Clinical Research Ethics Committee (Ref 2017.260).

\section{References}

1. Lessa FC, Mu Y, Bamberg WM, et al. Burden of Clostridium difficile infection in the United States. N Engl J Med 2015;372:825-34.

2. Khanna S, Shin A, Kelly CP. Management of Clostridium difficile infection in inflammatory bowel disease: expert review from the clinical practice updates committee of the AGA institute. Clin Gastroenterol Hepatol 2017;15:166-74.

3. Ho J, Dai RZ, Kwong TN, et al. Disease burden of Clostridium difficile infections in adults, Hong Kong, China, 2006-2014. Emerg Infect Dis 2017;23:1671-9. 
4. Wong SH, Ip M, Hawkey PM, et al. High morbidity and mortality of Clostridium difficile infection and its associations with ribotype 002 in Hong Kong. J Infect 2016;73:115-22.

5. Mylonakis E, Ryan ET, Calderwood SB. Clostridium difficile-associated diarrhea: a review. Arch Intern Med 2001;161:525-33.

6. Zuo T, Wong SH, Lam K, et al. Bacteriophage transfer during faecal microbiota transplantation in Clostridium difficile infection is associated with treatment outcome. Gut 2018;67:634-43.

7. McDonald LC, Gerding DN, Johnson S, et al. Clinical Practice Guidelines for Clostridium difficile infection in adults and children: 2017 update by the Infectious Diseases Society of America (IDSA) and Society for Healthcare Epidemiology of America (SHEA). Clin Infect Dis 2018;66:987-94.

8. Pépin J, Routhier S, Gagnon S, Brazeau I. Management and outcomes of a first recurrence of Clostridium difficileassociated disease in Quebec, Canada. Clin Infect Dis 2006;42:758-64.

9. Johnson S. Recurrent Clostridium difficile infection: a review of risk factors, treatments, and outcomes. J Infect 2009;58:403-10.

10. Cornely OA, Miller MA, Louie TJ, Crook DW, Gorbach SL. Treatment of first recurrence of Clostridium difficile infection: fidaxomicin versus vancomycin. Clin Infect Dis 2012;55 Suppl 2:154-61.

11. van Nood E, Vrieze A, Nieuwdorp M, et al. Duodenal infusion of donor feces for recurrent Clostridium difficile. N Engl J Med 2013;368:407-15.

12. Lai CY, Sung J, Cheng F, et al. Systematic review with meta-analysis: review of donor features, procedures and outcomes in 168 clinical studies of faecal microbiota transplantation. Aliment Pharmacol Ther 2019;49:354-63.

13. Woodworth MH, Neish EM, Miller NS, et al. Laboratory testing of donors and stool samples for fecal microbiota transplantation for recurrent Clostridium difficile infection. J Clin Microbiol 2017;55:1002-10.

14. Agha RA, Borrelli MR, Farwana R, et al. The PROCESS 2018 statement: updating consensus Preferred Reporting Of CasE Series in Surgery (PROCESS) guidelines. Int J Surg 2018;60:279-82.

15. Cammarota G, Ianiro G, Tilg H, et al. European consensus conference on faecal microbiota transplantation in clinical practice. Gut 2017;66:569-80.

16. Seekatz AM, Aas J, Gessert CE, et al. Recovery of the gut microbiome following fecal microbiota transplantation. MBio 2014;5:e00893-14.

17. Borren NZ, Ghadermarzi S, Hutfless S, Ananthakrishnan AN. The emergence of Clostridium difficile infection in Asia: a systematic review and meta-analysis of incidence and impact. PLoS One 2017;12:e0176797.

18. Census and Statistics Department, Hong Kong SAR Government. Hong Kong population projection 2004-2033, report of the task force on population policy. Available from: https://www.censtatd.gov.hk/media_workers_corner/ pc_rm/hong_kong_population_projections_2004_2033_/ index.jsp. Accessed 8 Mar 2019.

19. Lui RN, Ng SC. The same intestinal inflammatory disease despite different genetic risk factors in the East and West? Inflamm Intest Dis 2016;1:78-84.

20. Costello SP, Tucker EC, La Brooy J, Schoeman MN, Andrews JM. Establishing a fecal microbiota transplant service for the treatment of Clostridium difficile infection. Clin Infect Dis 2016;62:908-14.

21. Guidance for industry: enforcement policy regarding investigational new drug requirements for use of fecal microbiota for transplantation to treat Clostridium difficile infection not responsive to standard therapies. Food and Drug Administration, US Department of Health and Human Services, US Government; 2016. 